\title{
Improving English Literacy Skills for Lower-ability Students in Late French Immersion
}

\author{
Julie Cornett-Ching \\ Penticton School District \\ Penticton, BC, Canada
}

\author{
Grant Lenarduzzi \\ Gonzaga University \\ Spokane, WA, USA
}

\begin{abstract}
The purpose of this study was to increase the English Reading comprehension skills for lowerability students in Late French Immersion (LFI) through the use of Direct Instruction (DI) French Literacy support. The investigation was conducted in a semi-urban school district in British Columbia, Canada. The setting was a middle school operating a Grade 6-8 LFI program and the study occurred at the Grade 7 level, comprised of 82 students. The effects of DI French Literacy support were evaluated by a pretest-posttest quasi-experimental design. Lower-ability students demonstrated improved English Reading comprehension skills. The study illustrates that lower-ability students, who are atrisk, can attain proficient English Literacy skills while remaining in a Late French Immersion program. (Key words: Late French Immersion, Literacy, Reading comprehension, at-risk, lowerability, French Immersion)
\end{abstract}

\section{Introduction}

French Immersion (FI) in Canada started as a means to promote bilingualism [1]. As the demand for FI increased, the number of students in FI programs has grown, and there has been an influx of more diverse students. In some school districts FI programs have developed a perception for being more suited for above-average, motivated students. Teacher and French Department discussions, in the setting for this investigation, repeatedly revolved around the increasing number of students of lower academic ability entering the program. A commonly expressed opinion among the FI teachers was that every student must have competent English language skills to benefit from being in a FI program.

One of the major goals of the school district is to improve the Literacy of all students. It was expected that by providing strong French Literacy support for the weaker students within the LFI program that their English Literacy would improve. Currently, in the LFI program for this study, students struggling in LFI are encouraged to exit the program to focus on their English language skills. This student removal selectively gleans the LFI program and it was observed that few students improved or performed better in the English program. These same students expressed that the FI teachers had "given up" on them. This observation was also identified by Genesse (2004) where students of low academic ability who left the FI program continued to score below average in the English program.

French Immersion instruction improves academic achievement [1, 2, 3, 4]. Genesse's work demonstrated that FI students who have designated learning disabilities should be allowed entry into FI programs as the experience improves reading acquisition and comprehension, and second language proficiency, showing that low academic ability is no more a handicap in the FI program than it is in English programs [2]. Although it can be expected that students may struggle in a FI program they still gain knowledge and proficiency in both their first and second languages [5] and in Reading [6, 7].

When FI teachers or programs encourage students to leave the program it is implied that the student is not capable, when more support and differentiated instruction needs to be implemented [8]. This pushing out of students also suggests that schools and curriculum are designed for higher socioeconomic students [9]. Educators need to realize that "in general students with special needs have the same entitlements to be in the French Immersion program as in any other program in any public school or funded independent school" [10]. To support this end, the purpose of this study was to increase the English Reading comprehension skills for lower-ability students in Late French Immersion (LFI) through the use of Direct Instruction French Literacy support.

\section{Method}

The investigation took place in a dual-track middle level school, Grades 6-8, situated in an urban residential area within a semi-urban district. The school's population consisted of 300 LFI students and 150 English students. The majority of FI students came from affluent backgrounds and are bussed in from all regions of the district. The English track students are mostly from lower socio-economic demographics that live in the downtown core. Eighty-two (82) Grade 7 LFI students participated in 
the study. These students were in their second year of the LFI program.

There was nonrandom assignment to two groups based on (a) their performance on an English Reading comprehension assessment that was administered at the start of the school year to all Grade 7 LFI students, and (b) consultation with the classroom teachers. Students who scored poorly in Reading comprehension and were deemed to be struggling in the LFI program were considered to be of lower-ability academically and were assigned to the experimental group which received intervention support. The experimental group consisted of 11 students, while the control group had 71. All of the participants remained in their regular instructional setting.

The control group received no additional intervention. The remediated group received the DI French Literacy support as a group in the learning resource room within the school building. Direct Instruction has been shown to be an effective instructional strategy when improving the performance and skills of special needs students [11, 12]. The first author had 18 years of FI teaching experience and qualifications for teaching special needs children.

The intended outcome was to improve the English Reading comprehension skills of the lower-ability students as a result of receiving additional French Literacy instruction. The dependent variable was performance in Reading comprehension as assessed by the Performance Standards for the Province of BC. Student performance was scored on a scale of 1through 4, corresponding to: (a) not yet meeting, a score of 1; (b) minimally meeting, 2; (c) fully meeting, 3; and (d) exceeding expectations, a score of 4 .

The first author evaluated the student pre- and posttests, and delivered the French Literacy remediation. The DI instruction consisted of 26 pullout sessions, each 50 minutes in duration, over a period of eleven weeks in the fall semester. The students in the small group sessions were instructed in predicting and inferencing, summarizing and organizing, and main idea and comprehension skills. Following instruction, each student would (a) read a different story, (b) develop comprehension responses, (c) self-assess their responses, and (d) add to and enrich their responses using provided student exemplars for that story.

Analysis of performance changes between the experimental and control group, using an unpaired ttest, was conducted. The data for the experimental group, comparing their pretest and posttest results, was also examined, using a paired t-test.

\section{Results}

This study investigated the effect of French Literacy support on English Reading comprehension. Eighty-one (81) Grade 7 LFI students were given a pretest English Reading comprehension assessment at the start of the school year. This initial population was divided into two groups. The experimental group consisting of 11 students was determined to be in need of intervention and support.

The treatment group had a pretest mean of 1.91 on a four-point scale. After receiving three months of French Literacy support, the group's posttest mean was 2.55, a very statistically significant improvement, $t(20)=4.183, p=0.0019,95 \%$ confidence interval from -0.98 to -0.30 . Table 1 (Pretest and posttest means and standard deviations) displays the means and standard deviations. Figure 1 (Experimental group - reading comprehension pretest and posttest results) graphically illustrates the positive shift in performance.

The control group had a pretest mean of 2.54 and a posttest mean of 2.93. This was a positive shift in performance (see Figure 2- Control group - reading comprehension pretest and posttest results) but not as dramatic as the performance of the group receiving intervention.

Pertaining to the posttest performances of both groups each attained a similar level of achievement. The control and experimental group's attained mean scores of 2.93 and 2.55 respectively. The unpaired ttest indicated a not quite statistical significance between performance of the two groups on posttest achievement, $t(79)=1.93, p=0.0568$. The students in the treatment group closed the achievement gap in Reading comprehension after receiving three months of DI French Literacy support. This indicated a remarkable attainment for the treatment group.



Figure 1. Experimental group reading comprehension 


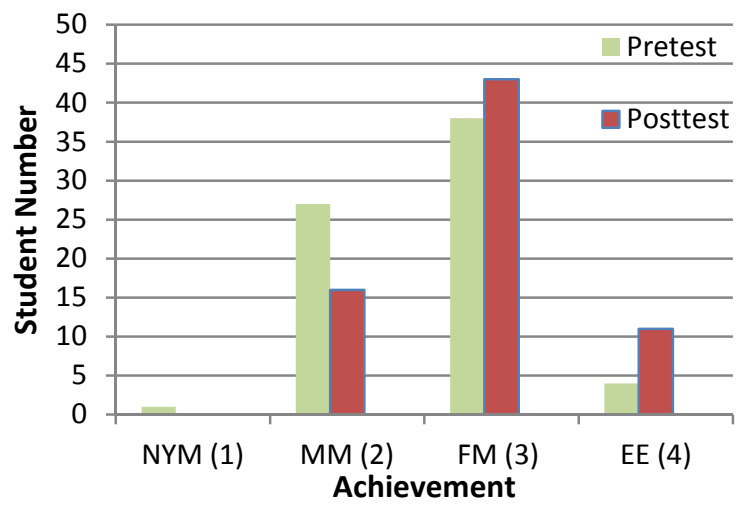

Figure 2. Control group reading comprehension

Table 1. Pretest and posttest means and standard deviations for experimental and control groups

$\begin{array}{lllll} & \text { E - Pre } & \text { E - Post } & \text { C - Pre } & \text { C - Post } \\ \text { Mean } & 1.91 & 2.55 & 2.54 & 2.93 \\ \text { SD } & 0.54 & 0.52 & 0.62 & 0.62 \\ \text { N } & 11 & 11 & 70 & 70\end{array}$

\section{Discussion}

The use of Direct Instruction French Literacy instruction seemed to be effective in improving English Literacy. The experimental group of eleven lower-ability Grade 7 Late French Immersion students showed significant improvement in English Reading comprehension after receiving a three month remediation program. In comparison to the control group of the remaining general population of Grade 7 LFI students, the intervention group had a marked increase in their performance with posttest mean scores that were similar to the regular LFI students.

The purpose of this study was to increase the English Reading comprehension skills for lowerability students in Late French Immersion (LFI) through the use of Direct Instruction French Literacy support. This did occur. The result of this study is analogous to previous research where academic abilities are shown to improve as a result of French Immersion instruction [1, 2, 3, 4]. Also parallel is that struggling FI students do improve their competencies in both languages [5] and on measures of Reading [6, 7]. This study had a number of strengths. The remediation for the experimental group was feasible in that it was financially economical and manageable to implement. The study employed a short and concentrated intervention that produced a significant improvement in student performance. Student participation was strong as they applied themselves diligently for the first author.

There were also some limitations in this current investigation. The time period was relatively short as the intervention was engaged for only three months prior to the posttest data being gathered. Performance data was restricted to English Reading comprehension and other facets of Literacy were excluded. Participation was constrained to one school site, at one grade level.

For the purposes of study duplication it would be beneficial to have a longer period of intervention with the possibility of mid-year and year-end data gathering. Pushing the investigation longitudinally into a Grade 8 follow-up on Literacy skills retention would be an advantage. The insight developed by this study could be supported by aspects of mixed methods such as including teacher interviews and student products. Adding additional measures of Literacy in both English and French a second marker to ground the standard of student performance would assist with reliability. The insight developed by this study could be supported by methods such as teacher interviews and student products. Adding further measures of Literacy in both English and French may provide additional impressive results.

The impetus for this investigation came from a desire to show that it was appropriate to place and retain struggling students in French Immersion programs. The finding in this study will assist in developing this as a common understanding for greater numbers of FI teachers and for school districts offering such programs. The data demonstrated that lower-ability students, who receive modest and manageable intervention support, can attain a similar level of Literacy proficiency as their peers, and stay in French Immersion programs to receive the benefits of such a placement.

\section{References}

[1] Allen, M. "Does French Immersion Improve Reading Achievement?”, Canadian Social Trends, 2004, http://search.ebscohost.com/login.aspx?direct=true\&db=f5 h\&AN=14532390\&site=ehost-live (5 November 2010).

[2] Genesee, F. "The Suitability of French Immersion for Students who are At-risk: A Review of Research Evidence”, Canadian Modern Language Review, (63)5, 2004, pp. 335-357.

[3] Lindholm-Leary, K. J. "Review of Research and Best Practices on Effective Features of Dual Language Education”, 2000, http://www.lindholmleary.com/resources/review_research.pdf (9 December 2010).

[4] Megherbi, H., Seigneuric, A. and Ehrlich, M. "Reading Comprehension in French $1^{\text {st }}$ and $2^{\text {nd }}$ Grade Children: Contribution of decoding and language 
comprehension”, European Journal of Psychology of Education - EJPE (Instituto Superior De Psicologia Aplicado) 21(2), 2006, pp. 135-147.

[5] Spivey, M. and Marian, V. “Cross Talk between Native and Second Languages: Partial Activation of an Irrelevant Lexicon”, Psychology Science 10(3), 1999, pp. 281-284.

[6] Caldas, S. J. and Bourdeaux, N. "Povery, Race and Foreign Language Immersion: Predictors of Math and English Language Arts Performance”, Learning Languages 5(1), 1999, pp. 4-15.

[7] Robinson, D. W. The Cognitive, Academic, and Attitudinal Benefits of Early Language Learning in M. Met (ed.) Critical Issues in Early Language Learning, Scott Foresman Addison Wesley: Glenview, IL, 1998.

[8] Juel, C. and Minden-Cupp, C. "Learning to Read Words: Linguistics, Units and Instructional Strategies", Reading Research Quarterly 35, 2000, pp. 458-492.

[9] Makropoulos, J. "Students' Attitudes of the Secondary French Immersion Curriculum in a Canadian Context”, Language Culture Curriculum 23, 2010, pp. 1-13.

[10] Manitoba Ministry of Education, French Immersion in Manitoba: A Handbook for School Leaders, Government of Manitoba, 2008, www.edu.gov.mb.ca/k12/docs/fr_imm_handbook/index.ht ml (8 May 2010)

[11] Gersten, R. "Teaching Reading Comprehension Strategies to Students with Learning Disabilities: A Review of the Research", Review of Educational Research 71(2), 2001, pp. 279-320.

[12] Kroesbergen, E. H. and Van Luit, J. E. H. "Mathematical Interventions for Children with Special Educational Needs", Remedial Special Education 24, 2003, pp. 97-114. 